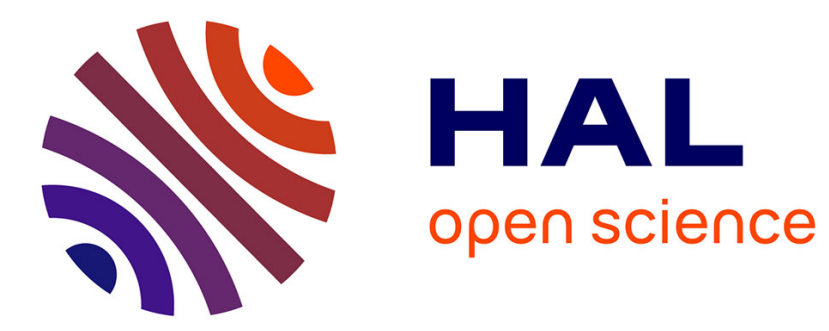

\title{
Systematic control of an electropneumatic system: Integrator backstepping and sliding mode control
}

\author{
Mohamed Smaoui, Xavier Brun, Daniel Thomasset
}

\section{To cite this version:}

Mohamed Smaoui, Xavier Brun, Daniel Thomasset. Systematic control of an electropneumatic system: Integrator backstepping and sliding mode control. IEEE Transactions on Control Systems Technology, 2006, 14 (5), pp.905-913. 10.1109/TCST.2006.880183 . hal-00140641

\section{HAL Id: hal-00140641 https://hal.science/hal-00140641}

Submitted on 18 Apr 2007

HAL is a multi-disciplinary open access archive for the deposit and dissemination of scientific research documents, whether they are published or not. The documents may come from teaching and research institutions in France or abroad, or from public or private research centers.
L'archive ouverte pluridisciplinaire HAL, est destinée au dépôt et à la diffusion de documents scientifiques de niveau recherche, publiés ou non, émanant des établissements d'enseignement et de recherche français ou étrangers, des laboratoires publics ou privés. 


\title{
Systematic Control of an Electropneumatic System: Integrator Backstepping and Sliding Mode Control
}

\author{
Mohamed Smaoui, Xavier Brun, and Daniel Thomasset
}

\begin{abstract}
This paper presents a synthesis of a nonlinear controller to an electropneumatic system. Nonlinear backstepping control and nonlinear sliding mode control laws are applied to the system under consideration. First, the nonlinear model of the electropneumatic system is presented. It is transformed to be a nonlinear affine model and a coordinate transformation is then made possible by the implementation of the nonlinear controller. Two kinds of nonlinear control laws are developed to track the desired position and desired pressure. Experimental results are also presented and discussed.
\end{abstract}

Index Terms-Backstepping control, electropneumatic actuator, sliding mode control.

\section{NOMENCLATURE}

$b \quad$ Viscous friction coefficient $(\mathrm{N} / \mathrm{m} / \mathrm{s})$.

$F_{\text {ext }} \quad$ External force $(\mathrm{N})$.

$k \quad$ Polytropic constant.

$l \quad$ Length of stroke (m).

$M \quad$ Total load mass $(\mathrm{kg})$.

$p_{P}$ or $N \quad$ Pressure in the cylinder chamber $P$ or $N(\mathrm{~Pa})$.

$q_{m} \quad$ Mass flow rate provided from servodistributor to cylinder chamber $(\mathrm{kg} / \mathrm{s})$.

$r \quad$ Perfect gas constant related to unit mass $(\mathrm{J} / \mathrm{kg} / \mathrm{K})$.

$S_{P}$ or $N \quad$ Area of the piston cylinder on the chamber $P$ or $N\left(\mathrm{~m}^{2}\right)$.

$T \quad$ Temperature $(\mathrm{K})$.

$V \quad$ Volume $\left(\mathrm{m}^{3}\right)$.

$U \quad$ Input voltage (V).

$y, v, a, j$ Position $(\mathrm{m})$, velocity $(\mathrm{m} / \mathrm{s})$, acceleration $\left(\mathrm{m} / \mathrm{s}^{2}\right)$, jerk $\left(\mathrm{m} / \mathrm{s}^{3}\right)$.

$\varphi(\cdot) \quad$ Leakage polynomial function $(\mathrm{kg} / \mathrm{s})$.

$\psi(\cdot) \quad$ Polynomial function $(\mathrm{kg} / \mathrm{s} / \mathrm{V})$.

\section{Subscript}

ext External.

$D$ Dead volume.

$S$ Supply.

$N$ Chamber $\mathrm{N}$.

Manuscript received July 7, 2003; revised February 28, 2005. Manuscript received in final form May 9, 2006. Recommended by Associate Editor S. Ge.

The authors are with the Laboratoire d'Automatique Industrielle, Institut National des Sciences Appliquiées de Lyon (INSA), Bât Antoine de Saint-Exupery, 69621 Villeurbanne Cedex, France (e-mail: mohamed.smaoui@insa-lyon.fr).

Digital Object Identifier 10.1109/TCST.2006.880183
$\begin{array}{ll}P & \text { Chamber P. } \\ \text { d } & \text { Desired. }\end{array}$

\section{INTRODUCTION}

$\mathbf{P}$ NEUMATIC control systems play an important role in industrial automation due to their relatively small size, light weight, and high speed.

One of the conspicuous trends is the need for the electropneumatic systems that can achieve precise tracking position control [1].

The traditional and widely used approach to the control of electropneumatic systems is a fixed-gain linear controller based on the local linearization of the nonlinear dynamics around a nominal operating point [2]. This method relies on the key assumption of small range operation for the linear model to be valid. When the required operation range is large, the linear controller is likely to perform poorly. The harmful effects are due to the limitation of the linear feedback controller tolerance for the adverse effect of the nonlinearities or parameter variations.

When a fixed-gain linear controller cannot satisfy the control requirement, it is natural to investigate other controllers. In recent years, research efforts have been directed toward meeting this requirement. Most of them are feedback linearization [3]. However, a reasonably accurate mathematical model for the pneumatic system is required for feedback linearization.

A number of investigations have been reported on fuzzy control algorithms [4], adaptive control [5], sliding mode control [6], [7], and robust linear control [8].

Generally, for pneumatic control systems, the application is position control, pressure control, or a combination of the two such that an algorithm smoothly switches from closed-loop position control to closed-loop force control [9].

The main contribution of this paper consists of designing a multi-input/multi-output (MIMO) backstepping and sliding mode control laws for electropneumatic system in order to track the desired position and desired pressure in one of the actuator chambers. A solution using a classic feedback law has been developed in [10], where the architecture of the process is modified with respect to both specifications for position and pressure tracking and criteria concerning the energy assumption.

In this paper, robust nonlinear controllers have been studied. The model of the electropneumatic system has been presented and equations governing the motion of this plant have been put in a nonlinear affine form. In order to use the backstepping and the sliding mode techniques, a coordinate transformation has been proposed.

Section II describes the model of the electropneumatic actuator and states the problem under study. Section III deals with the design of the two control laws. Section IV will be devoted to 

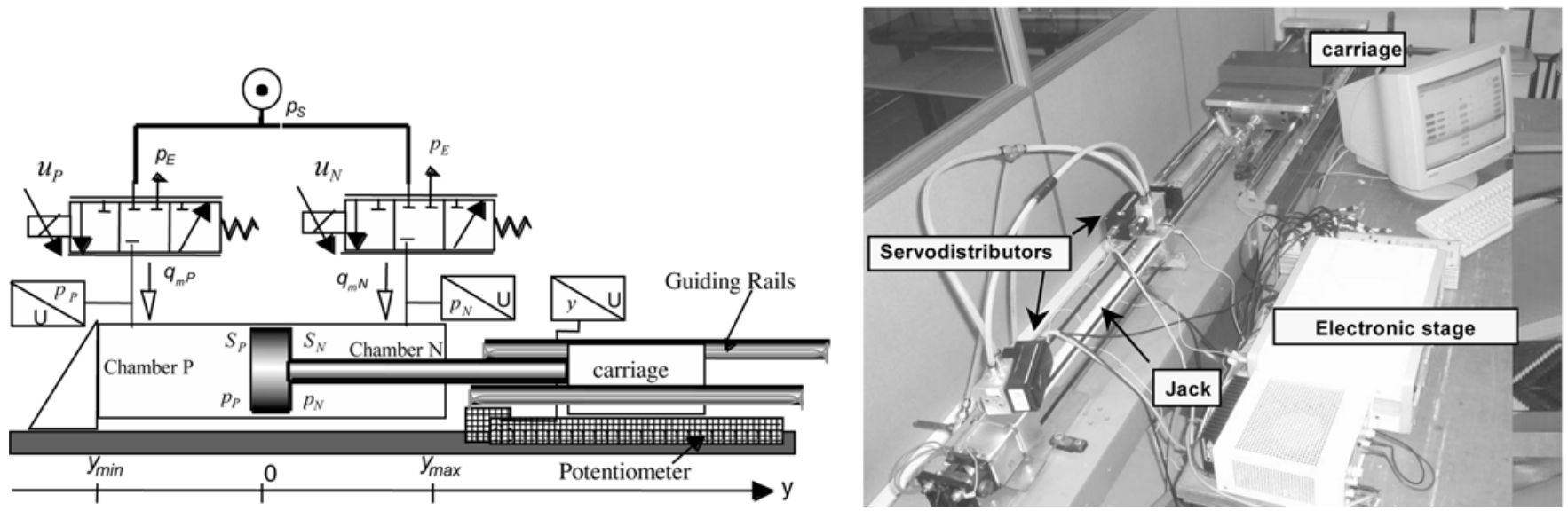

Fig. 1. Electropneumatic system.

the experimental results. Both sets of results will be compared with an industrial benchmark. Section V concludes this paper.

\section{Electropneumatic System ModELing}

The electropneumatic system (Fig. 1) uses the following structure: two three-way proportional servodistributors/and actuator/and mass in translation. The actuator under consideration is an inline electropneumatic cylinder using a simple rod $(32 / 20 \mathrm{~mm})$ with a stroke of $500 \mathrm{~mm}$. The rod is connected to one side of a carriage and drives an inertial load on guiding rails. The total moving mass is $17 \mathrm{~kg}$.

The electropneumatic system model can be obtained using three physical laws: the mass flow rate through a restriction, the pressure behavior in a chamber with variable volume, and the fundamental mechanical equation.

In our case, the bandwidth of the Servotronic Joucomatic servodistributor and actuator are, respectively, about 200 and 2, $4 \mathrm{~Hz}$. Using the singular perturbation theory, the dynamics of the servodistributors are neglected and their model can be reduced to a static one, described by two relationships $q_{m^{P}}\left(u_{P}, p_{P}\right)$ and $q_{m^{N}}\left(u_{N}, p_{N}\right)$ between the mass flow rates $q_{m} P$ and $q_{m} N$, the input voltages $u_{P}$ and $u_{N}$, and the output pressures $p_{P}$ and $p_{N}$. The pressure evolution law in a chamber with variable volume is obtained assuming the following assumptions [11]: air is a perfect gas and its kinetic energy is negligible; the pressure and the temperature are homogeneous in each chamber; and the process is polytropic and characterized by a coefficient $k$. Moreover, the electropneumatic system model is obtained by combining all the previous relations and assuming that the temperature variation is negligible with respect to average and equal to the supply temperature. Therefore, the following relations give the model of the previous system:

$$
\left\{\begin{array}{l}
\frac{d y}{d t}=v \\
\frac{d v}{d t}=\frac{1}{M}\left[S_{P} p_{P}-S_{N} p_{N}-b v-F_{\mathrm{ext}}\right] \\
\frac{d p_{P}}{d t}=\frac{k r T}{V_{P}(y)}\left[q_{m P}\left(u_{P}, p_{P}\right)-\frac{S_{P}}{r T} p_{P} v\right] \\
\frac{d p_{N}}{d t}=\frac{k r T}{V_{N}(y)}\left[q_{m N}\left(u_{N}, p_{N}\right)+\frac{S_{N}}{r T} p_{N} v\right]
\end{array}\right.
$$

where

$$
\left\{\begin{array} { l } 
{ V _ { P } ( y ) = V _ { P } ( 0 ) + S _ { P } y } \\
{ V _ { N } ( y ) = V _ { N } ( 0 ) - S _ { N } y }
\end{array} \quad \text { with: } \left\{\begin{array}{l}
V_{p}(0)=V_{\mathrm{DP}}+S_{P} \frac{l}{2} \\
V_{N}(0)=V_{\mathrm{DN}}+S_{N} \frac{l}{2}
\end{array}\right.\right.
$$

are the effective volumes of the chambers for the zero position and $V_{D[P}$ or $\left.N\right]$ are dead volumes present at each extremity of the cylinder.

The main difficulty for model (1) is to know the mass flow rates $q_{m P}$ and $q_{m N}$.

In order to establish a mathematical model of the power modulator flow stage, many research works present approximations based on physical laws [12] by modeling the geometrical variations of the restriction areas of the servodistributor, as well as by experimental characterization [13].

In this paper, the results of the global experimental method giving the static characteristics of the flow stage [14] have been used. The global characterization corresponds to the static measurement of the output mass flow rate $q_{m}$ which depends on the input control $u$ and the output pressure $p$ for a constant source pressure. The global characterization has the advantage of obtaining simply, by projection of the characteristic series $q_{m}(u, p)$ on different planes:

- mass flow rate characteristics series (plane $p-q_{m}$ );

- mass flow gain characteristics series (plane $u-q_{m}$ );

- pressure gain characteristics series (plane $u-p$ ).

The authors in [15] have developed analytical models for both simulation and control purposes. Two cases have been studied to approximate the flow stage characteristics by polynomial functions:

- multivariable polynomial function;

- polynomial approximation affine in control such that

$$
q_{m}(u, p)=\varphi(p)+\psi(p, \operatorname{sgn}(u)) u
$$

$\psi(\cdot)>0$ over the physical domain.

By using the first approximation, a nonaffine nonlinear model is obtained. In this case, some control algorithms, such as adaptive neural network controllers [16], [17] can be used.

In this paper, the second approximation is used because it enables a physical significance to be given to the polynomial functions. $\varphi(p)$ in (2) is a polynomial function of the pressure 
whose evolution corresponds to the mass flow rate leakage and does not depend on the input control. $\psi(p, \operatorname{sgn}(u))$ is a polynomial function of both the pressure and sgn of the input control, because the behavior of the mass flow rate characteristics are clearly different for the inlet $(u>0)$ and the exhaust $(u<0)$. The polynomial functions $\varphi(p), \psi(p, u>0), \psi(p, u<0)$ have five degrees.

From the (2) the nonlinear affine model is then given by the equation

$$
\left\{\begin{aligned}
\frac{d y}{d t}= & v \\
\frac{d v}{d t}= & \frac{1}{M}\left[S_{P} p_{P}-S_{N} p_{N}-b v-F_{\mathrm{ext}}\right] \\
\frac{d p_{P}}{d t}= & \frac{k r T}{V_{P}(y)}\left[\varphi\left(p_{P}\right)-\frac{S_{P}}{r T} p_{P} v\right] \\
& +\frac{k r T}{V_{P}(y)} \psi\left(p_{P}, \operatorname{sgn}\left(u_{P}\right)\right) u_{P} \\
\frac{d p_{N}}{d t}= & \frac{k r T}{V_{N}(y)}\left[\varphi\left(p_{N}\right)+\frac{S_{N}}{r T} p_{N} v\right] \\
& +\frac{k r T}{V_{N}(y)} \psi\left(p_{N}, \operatorname{sgn}\left(u_{N}\right)\right) u_{N} .
\end{aligned}\right.
$$

With two inputs $u_{P}$ and $u_{N}$, the nonlinear model of the system in Fig. 1 has the following form:

$$
\underline{\dot{x}}=f(\underline{x})+g(\underline{x}) \times U
$$

with

$$
\underline{x}=\left(y, v, p_{P}, p_{N}\right)^{T}
$$

where

$$
\begin{aligned}
& f(\underline{x})=\left(\begin{array}{c}
v \\
\frac{1}{M}\left[S_{P} p_{P}-S_{N} p_{N}-b v-F_{\mathrm{ext}}\right] \\
\frac{k r T}{V_{P}(y)}\left[\varphi\left(p_{P}\right)-\frac{S_{P}}{r T} p_{P} v\right] \\
\frac{k r T}{V_{N}(y)}\left[\varphi\left(p_{N}\right)+\frac{S_{N}}{r T} p_{N} v\right]
\end{array}\right) \\
& g(\underline{x})=\left[g_{1}(\underline{x}), g_{2}(\underline{x})\right] \\
& =\left(\begin{array}{cc}
0 & 0 \\
0 & 0 \\
\frac{k r T}{V_{P}(y)} \psi\left(p_{P}, \operatorname{sgn}\left(u_{P}\right)\right) & 0 \\
0 & \frac{k r T}{V_{N}(y)} \psi\left(p_{N}, \operatorname{sgn}\left(u_{N}\right)\right)
\end{array}\right) \\
& U=\left(u_{P}, u_{N}\right)^{T} \text {. }
\end{aligned}
$$

The system uses two three-way proportional servodistributors. Generally, it is supposed that these two servodistributors are equivalent to one five-way proportional servodistributor when they are controlled with the inputs of opposite signs [2]. In this case, a monovariable position control law can be established. However, the validity of the control law depends on the stability of the unobservable subsystem, which is one-dimensional (1-D). It is very difficult to obtain results about the global stability of the zero dynamics.

With a system of two three-way servodistributors, it is possible to control two different trajectories. For example, it seems useful to control position and pressure without a degradation of the desired specifications (tracking position). Let us define $h(\underline{x})$ the vector consisting of the two chosen outputs: position and pressure in chamber $P$

$$
h(\underline{x})=\left(\begin{array}{c}
h_{1}(\underline{x}) \\
h_{2}(\underline{x})
\end{array}\right)=\left(\begin{array}{c}
y \\
p_{P}
\end{array}\right) .
$$

The relative degree associated to the position and the pressure are, respectively, three and one. Thus, the sum is equal to the dimension of the system. This is sufficient to affirm that the system is differentially flat [18]. In order to use a backstepping technique and a sliding mode technique, a coordinate transformation is proposed as follows:

$$
\begin{aligned}
& \underline{z}=\phi(\underline{x})=\left[\begin{array}{c}
h_{1}(\underline{x})=y \\
L_{f} h_{1}(\underline{x})=v \\
L_{f}^{2} h_{1}(\underline{x})=a \\
h_{2}(\underline{x})=p_{P}
\end{array}\right] \\
& \left\{\begin{array}{l}
\frac{d y}{d t}=v \\
\frac{d v}{d t}=a \\
\frac{d a}{d t}=L_{f}^{3} h_{1}\left(\phi^{-1}(\underline{z})\right)+L_{g_{1}} L_{f}^{2} h_{1}\left(\phi^{-1}(\underline{z})\right) u_{p} \\
\quad+L_{g_{2}} L_{f}^{2} h_{1}\left(\phi^{-1}(\underline{z})\right) u_{N} \\
\frac{d p_{p}}{d t}=L_{f} h_{2}\left(\phi^{-1}(\underline{z})\right)+L_{g_{1}} h_{2}\left(\phi^{-1}(\underline{z})\right) u_{P}
\end{array}\right.
\end{aligned}
$$

where

$$
\begin{aligned}
L_{f}^{3} h_{1}(\underline{x})= & \frac{k r T}{M}\left(\frac{S_{p}}{V_{p}(y)} \phi\left(p_{P}\right)-\frac{S_{N}}{V_{N}(y)} \phi\left(P_{N}\right)\right) \\
& -\frac{b}{M^{2}}\left(S_{P} p_{P}-S_{N} p_{N}-b v-F_{\mathrm{ext}}\right) \\
& -\frac{k v}{M}\left(\frac{S_{p}^{2} p_{P}}{V_{P}(y)}+\frac{S_{N}^{2} p_{N}}{V_{N}(y)}\right) \\
= & L_{1}(\underline{x})+L_{2}(\underline{x}) \\
L_{g_{1}} L_{f}^{2} h_{1}(\underline{x})= & \frac{k r T S_{P}}{M V_{P}(y)} \psi\left(p_{P}, \operatorname{sign}\left(u_{P}\right)\right)>0 \\
L_{g_{2}} L_{f}^{2} h_{1}(\underline{x})= & -\frac{k r T S_{N}}{M V_{N}(y)} \psi\left(p_{N}, \operatorname{sgn}\left(u_{N}\right)\right)<0 \\
L_{f} h_{2}(x)= & \frac{k r T}{V_{P}(y)} \varphi\left(p_{P}\right)-\frac{k_{P}}{V_{P}(y)} p_{P} v \\
= & L_{3}(\underline{x})+L_{4}(\underline{x}) \\
L_{g_{1}} h_{2}(\underline{x})= & \frac{k r T}{V_{P}(y)} \psi\left(p_{P}, \operatorname{sgn}\left(u_{P}\right)\right)>0 \\
L_{g_{2}} h_{2}(\underline{x})= & 0
\end{aligned}
$$

with

$$
\begin{aligned}
L_{1}(\underline{x})= & \frac{k r T}{M}\left(\frac{S_{p}}{V_{p}(y)} \varphi\left(p_{p}\right)-\frac{S_{N}}{V_{N}(y)} \varphi\left(p_{N}\right)\right) \\
& -\frac{b}{M^{2}}\left(S_{P} p_{P}-S_{N} p_{N}-b v-F_{\mathrm{ext}}\right) \\
L_{2}(\underline{x})= & -\frac{k v}{M}\left(\frac{S_{p}^{2} p_{P}}{V_{P}(y)}+\frac{S_{N}^{2} p_{N}}{V_{N}(y)}\right) \\
L_{3}(\underline{x})= & \frac{k r T}{V_{P}(y)} \varphi\left(p_{P}\right) \\
L_{4}(\underline{x})= & -\frac{k S_{P}}{V_{P}(y)} p_{P} v .
\end{aligned}
$$


The dynamics $L_{1}(\underline{x})$ and $L_{3}(\underline{x})$ contain all the uncertainties, i.e., the leakage polynomial function and viscous friction. This is assumed to be bounded by two known functions $F_{1}(\underline{x})$ and $F_{2}(\underline{x})$

$$
\begin{aligned}
\left|L_{1}(\underline{x})\right| & \leq F_{1}(\underline{x}) \\
\left|L_{3}(\underline{x})\right| & \leq F_{2}(\underline{x}) .
\end{aligned}
$$

In fact, $\varphi(p)$ represents the mass flow leakage inside the servodistributor and it is not easy to find a correct model for this part. Usually the maximum leakage value $|\varphi(p)|_{\max }$, is well known. In addition, the knowledge of the viscous friction coefficient $b$ has been identified and the variation of this coefficient around the nominal value has been experimentally evaluated at $30 \%$. Since all states are bounded, a positive constant $\delta$ exists so that $\left|(1 / M)\left(S_{P} p_{P}-S_{N} p_{N}-b v-F_{\text {ext }}\right)\right|<\delta . \delta$ represents the maximum value of acceleration $\left(25.3 \mathrm{~ms}^{-2}\right)$.

From all the above elements, it can be concluded that $F_{1}(\underline{x})$ and $F_{2}(\underline{x})$ can be given as

$$
\begin{aligned}
F_{1}(\underline{x})= & \frac{k r T}{M}\left(\frac{S_{p}}{V_{p}(y)}\left|\varphi\left(p_{p}\right)\right|_{\max }+\frac{S_{N}}{V_{N}(y)}\left|\varphi\left(p_{N}\right)\right|_{\max }\right) \\
& +\frac{b_{\max }}{M} \delta \\
F_{2}(\underline{x})= & \frac{k r T}{V_{P}(y)}\left|\varphi\left(p_{P}\right)\right|_{\max } .
\end{aligned}
$$

Due to uncertainties appearing in the model, robust controllers are necessary to ensure high precision position and pressure tracking. By using model (7), the objective consists of designing a MIMO backstepping and sliding control law for the electropneumatic system.

The aim of the control law is to respect good accuracy in terms of position and pressure tracking for desired trajectories. The relative degree of the position and the pressure are, respectively, three and one. This means that the electropneumatic system can only track position trajectories at least three times differentiable and pressure trajectories at least one time differentiable. The desired trajectories have been carefully chosen in order to respect these differentiability conditions (see Fig. 2).

\section{CONTROL SYNTHESIS}

\section{A. Multivariable Backstepping Controller}

Backstepping [19]-[21] is a recursive procedure, which enables a control law to be derived for a nonlinear system, associated to the appropriate Lyapunov function, which guarantees stability. Classes of systems, for which this procedure works, are given in [20] and [21].

In this paper, this technique is applied for a MIMO system (inputs: $u_{P}$ and $u_{N}$, outputs: $y$ and $P_{P}$ ).

First, a pressure error is defined

$$
e_{4}=p_{p}-p_{p}^{d}
$$

Differentiating (21) gives

$$
\frac{d e_{4}}{d t}=L_{f} h_{2}\left(\phi^{-1}(\underline{z})\right)+L_{g_{1}} h_{2}\left(\phi^{-1}(\underline{z})\right) u_{P}-\dot{P}_{p}^{d} .
$$

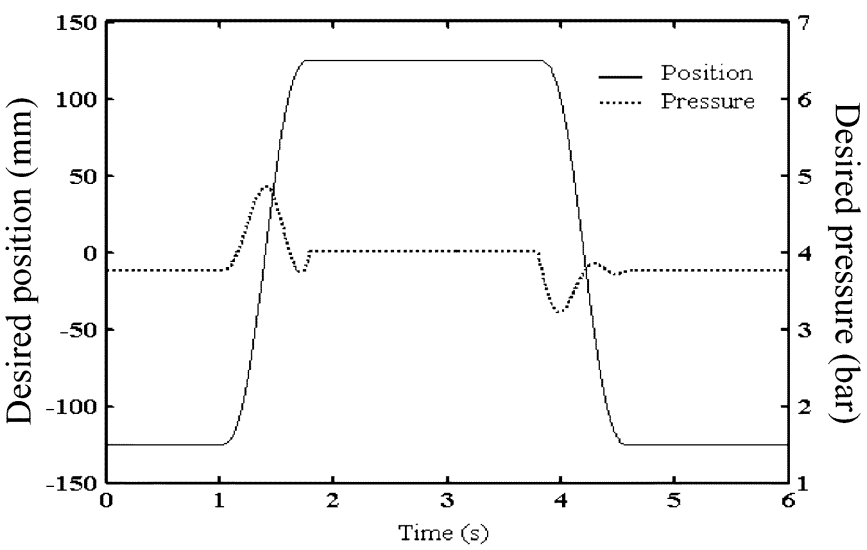

Fig. 2. Desired trajectories.

$u_{p}$ is chosen as

$$
\begin{aligned}
u_{p}= & \frac{1}{L_{g_{1}} h_{2}\left(\phi^{-1}(z)\right)} \\
& \times\left\{-F_{2}(\underline{x}) \operatorname{sgn}\left(e_{4}\right)+\frac{k S_{P}}{V_{P}(y)} p_{P} v+\dot{p}_{P}^{d}-c_{4} e_{4}\right\}
\end{aligned}
$$

with $c_{4}>0$.

Taking $V\left(e_{4}\right)=(1 / 2) e_{4}^{2}$ as a Lyapunov function, the derivative of this function reads

$$
\dot{V}\left(e_{4}\right)=-c_{4} e_{4}^{2}-F_{2}(\underline{x})\left|e_{4}\right|+\frac{k r T}{V_{P}(y)} \varphi\left(p_{P}\right) e_{4} \leq-c_{4} e_{4}^{2}<0 .
$$

Now, consider the scalar system

$$
e_{1}=y-y_{d}
$$

Differentiating (25) gives

$$
\dot{e}_{1}=v-v_{d}
$$

with $v$ viewed as the input, the feedback control $v=\alpha\left(z_{1}\right)$ is designed to stabilize the origin $e_{1}=0$ with

$$
v=-c_{1} e_{1}+v_{d}=\alpha_{1}\left(e_{1}, v_{d}\right)
$$

with $c_{1}>0$. Then (25) becomes

$$
\dot{e}_{1}=-c_{1} e_{1}
$$

and $V\left(e_{1}\right)=(1 / 2) e_{1}^{2}$ satisfies $\dot{V}\left(e_{1}\right)=-c_{1} e_{1}^{2}<0$. A velocity error is defined as follows:

$$
e_{2}=v-\alpha_{1}\left(e_{1}, v_{d}\right)=v-v_{d}+c_{1} e_{1} .
$$

The $(y, v)$-subsystem is transformed into the form

$$
\left\{\begin{array}{l}
\dot{e}_{1}=e_{2}-c_{1} e_{1} \\
\dot{e}_{2}=a-a_{d}+c_{1}\left(e_{2}-c_{1} e_{1}\right) .
\end{array}\right.
$$


Taking $V\left(e_{1}, e_{2}\right)=(1 / 2) e_{1}^{2}+(1 / 2) e_{2}^{2}$ as a composite Lyapunov function. The derivative of $\mathrm{V}\left(\mathrm{e}_{1}, \mathrm{e}_{2}\right)$ is computed as

$$
\dot{V}\left(e_{1}, e_{2}\right)=-c_{1} e_{1}^{2}+e_{2}\left(e_{1}+a-a_{d}+c_{1}\left(e_{2}-c_{1} e_{1}\right)\right. \text {. }
$$

Taking

$a=-e_{1}+a_{d}-c_{1}\left(e_{2}-c_{1} e_{1}\right)-c_{2} e_{2}=\alpha_{2}\left(e_{1}, e_{2}, a_{d}\right)$.

This ensures the negativity of the Lyapunov function

$$
\dot{V}\left(e_{1}, e_{2}\right)=\dot{V}\left(e_{1}\right)-c_{2} e_{2}^{2}=-c_{1} e_{1}^{2}-c_{2} e_{2}^{2}<0
$$

for some $c_{2}\left[s^{-1}\right]>0$. Finally, an acceleration error is defined as follows:

$$
e_{3}=a-\alpha_{2}\left(e_{1}, e_{2}, a_{d}\right)
$$

the $(y, v, a)$-subsystem is transformed into the form

$$
\left\{\begin{aligned}
\dot{e}_{1}= & e_{2}-c_{1} e_{1} \\
\dot{e}_{2}= & e_{3}-e_{1}-c_{2} e_{2} \\
\dot{e}_{3}= & L_{f}^{3} h_{1}\left(\phi^{-1}(\underline{z})\right)+L_{g_{1}} L_{f}^{2} h_{1}\left(\phi^{-1}(\underline{z})\right) u_{p} \\
& +L_{g_{2}} L_{f}^{2} h_{1}\left(\phi^{-1}(\underline{z})\right) u_{N}-j_{d}+\left(c_{1}+c_{2}\right)\left(e_{3}-e_{1}-c_{2} e_{2}\right) \\
& +\left(1-c_{1}^{2}\right)\left(e_{2}-c_{1} e_{1}\right) .
\end{aligned}\right.
$$

Using $V\left(e_{1}, e_{2}, e_{3}\right)=(1 / 2) e_{1}^{2}+(1 / 2) e_{2}^{2}+(1 / 2) e_{3}^{2}$ as a composite Lyapunov function, and taking

$$
\begin{aligned}
u_{N}= & \frac{1}{L_{g_{2}} L_{f}^{2} h_{1}\left(\phi^{-1}(\underline{z})\right)} \\
\times & {\left[-e_{2}-L_{2}\left(y, v, p_{p}, p_{N}\right)-F_{1}(\underline{x}) \operatorname{sgn}\left(e_{3}\right)\right.} \\
& -L_{g_{1}} L_{f}^{2} h_{1}\left(\phi^{-1}(\underline{z})\right) u_{p}+j_{d} \\
& -\left(c_{1}+c_{2}\right)\left(e_{3}-e_{1}-c_{2} e_{2}\right) \\
& \left.-\left(1-c_{1}^{2}\right)\left(e_{2}-c_{1} e_{1}\right)-c_{3} e_{3}\right]
\end{aligned}
$$

for some $c_{3}\left[s^{-1}\right]>0$. So, the derivative of the Lyapunov function becomes

$$
\begin{aligned}
\dot{V}\left(e_{1}, e_{2}, e_{3}, e_{4}\right)= & \dot{V}\left(e_{1}, e_{2}\right)-c_{3} e_{3}^{2}-F_{1}(\underline{x})\left|e_{3}\right| \\
& +L_{1}\left(y, p_{p}, p_{N}\right) e_{3} \\
\leq & -c_{1} e_{1}^{2}-c_{2} e_{2}^{2}-c_{3} e_{3}^{2} \\
< & 0
\end{aligned}
$$

Given the system described in (7) and using the actual inputs defined in (23) and (36), the output tracking error is globally asymptotically stable.

\section{B. Multivariable Sliding Mode Control (SMC)}

SMC [22]-[24] is one of the effective nonlinear robust approaches. The first step of sliding mode control is to select a sliding surface $\sigma_{i}$ that models the desired closed-loop performance in the state variable space. Then, design the control so that the system state trajectories are forced towards the sliding surface and stay on it. The choice of the control law that satisfies the following sliding condition is:

$$
\sigma_{i} \dot{\sigma}_{i}<0
$$

which ensures the attractivity of the sliding surface in the state space. The general problem is stated for a system represented by the state equation

$$
\underline{\dot{x}}=f(\underline{x})+g(\underline{x}) \times U
$$

where $\underline{x} \in \Re^{n}$ and $U \in \Re^{m}$. SMC design consists of finding $m$ switching functions. The sliding control law is obtained by forcing each control variable $u_{i}$ of the control vector to satisfy the following law

$$
u_{i}=\left\{\begin{array}{ll}
u_{i}^{+}, & \text {when } \sigma_{i}(x)>0 \\
u_{i}^{-}, & \text {when } \sigma_{i}(x)<0
\end{array} \quad i=1, \ldots, m .\right.
$$

So that the reaching modes satisfy the "reaching condition" namely, reach the set $\sigma_{i}(x)=0$ (switching surface) in finite time. Then, any state $x$ outside the switching surface is forced to reach the surface in finite time. On the switching surface, the sliding mode takes place following the desired system dynamics.

Let us define a vector $\sigma$ of components $\sigma_{i}(i=1,2)$ by

$$
\begin{aligned}
\sigma_{1} & =\lambda^{2}\left(y-y^{d}\right)+2 \lambda\left(v-v^{d}\right)+\left(a-a^{d}\right) \\
& =\lambda^{2} e_{y}+2 \lambda e_{v}+e_{a} \\
\sigma_{2} & =p_{P}-p_{P}^{d} \\
& =e_{P}
\end{aligned}
$$

with $\lambda>0$. Differentiating (41) and (42) gives

$$
\begin{aligned}
{\left[\begin{array}{c}
\dot{\sigma}_{1} \\
\dot{\sigma}_{2}
\end{array}\right]=} & {\left[\begin{array}{c}
\lambda^{2}\left(v-v^{d}\right)+2 \lambda\left(a-a^{d}\right)-j^{d}+L_{f}^{3} h_{1}\left(\phi^{-1}(\underline{z})\right) \\
L_{f} h_{2}\left(\phi^{-1}(\underline{z})\right)-\dot{p}_{P}^{d}
\end{array}\right] } \\
& +\left[\begin{array}{cc}
L_{g_{1}} L_{f}^{2} h_{1}\left(\phi^{-1}(\underline{z})\right) & L_{g_{2}} L_{f}^{2} h_{1}\left(\phi^{-1}(\underline{z})\right) \\
L_{g_{1}} h_{2}\left(\phi^{-1}(\underline{z})\right) & 0
\end{array}\right]\left[\begin{array}{c}
u_{P} \\
u_{N}
\end{array}\right] .
\end{aligned}
$$

The two control laws are chosen as follows

$$
\begin{aligned}
{\left[\begin{array}{c}
u_{P} \\
u_{N}
\end{array}\right]=} & {\left[\begin{array}{cc}
L_{g_{1}} L_{f}^{2} h_{1}\left(\phi^{-1}(z)\right) & L_{g_{2}} L_{f}^{2} h_{1}\left(\phi^{-1}(z)\right) \\
L_{g_{1}} h_{2}\left(\phi^{-1}(z)\right) & 0
\end{array}\right]^{-1} } \\
& \times\left(-\left[\begin{array}{cc}
\lambda^{2}\left(v-v^{d}\right)+2 \lambda\left(a-a^{d}\right)-j^{d}+L 2(\underline{z}) \\
L 4(\underline{z})-\dot{p}_{P}^{d}
\end{array}\right]\right. \\
& \left.-\left[\begin{array}{c}
\left(k_{1}+F_{1}(\underline{x})\right) \operatorname{sgn}\left(\sigma_{1}\right) \\
\left(k_{2}+F_{2}(\underline{x})\right) \operatorname{sgn}\left(\sigma_{2}\right)
\end{array}\right]\right)
\end{aligned}
$$

with $k_{i},(i=1,2)>0$.

This satisfies the sliding condition

$$
\begin{aligned}
& \sigma_{1} \dot{\sigma}_{1}=\sigma_{1}\left(L_{1}(\underline{z})-\left(k_{1}+F_{1}(\underline{x})\right) \operatorname{sgn}\left(\sigma_{1}\right)\right)<0 \\
& \sigma_{2} \dot{\sigma}_{2}=\sigma_{2}\left(L_{3}(\underline{z})-\left(k_{2}+F_{2}(\underline{x})\right) \operatorname{sgn}\left(\sigma_{2}\right)\right)<0 .
\end{aligned}
$$

It is important to note that $L_{g_{1}} h_{2}\left(\phi^{-1}(z)\right)$ is strictly positive and $L_{g_{2}} L_{f}^{2} h_{1}\left(\phi^{-1}(z)\right)$ is strictly negative, so there is no singularity in the control laws (23), (36), and (44).

\section{EXPERIMENTAL RESULTS}

The proposed backstepping algorithm has been implemented using a dSpace DS1104 controller board with a dedicated digital signal processor. The measured signals, all analog, were run 


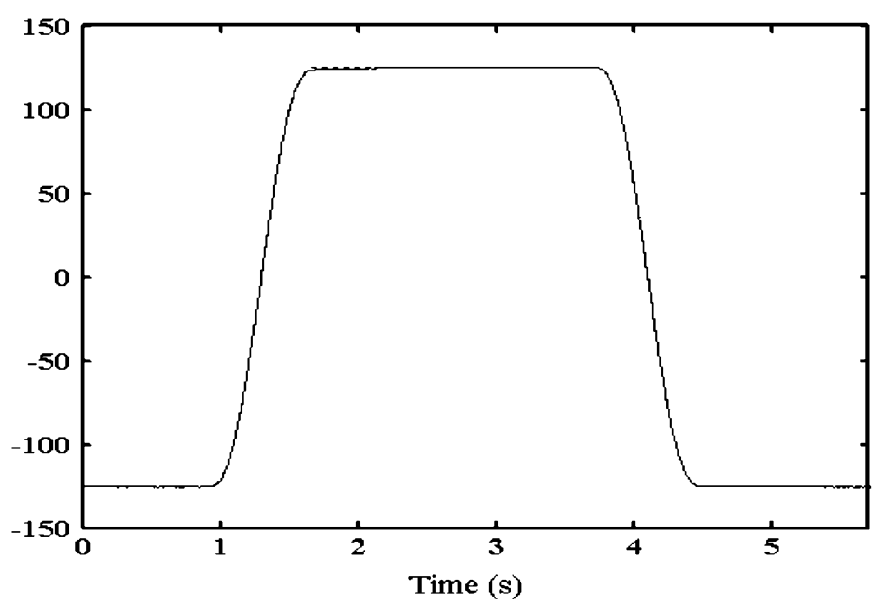

(a)

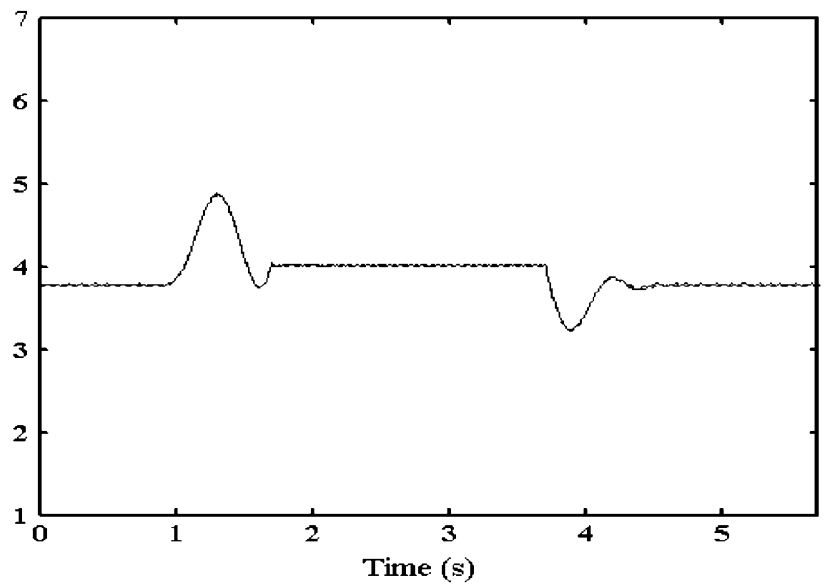

(c)

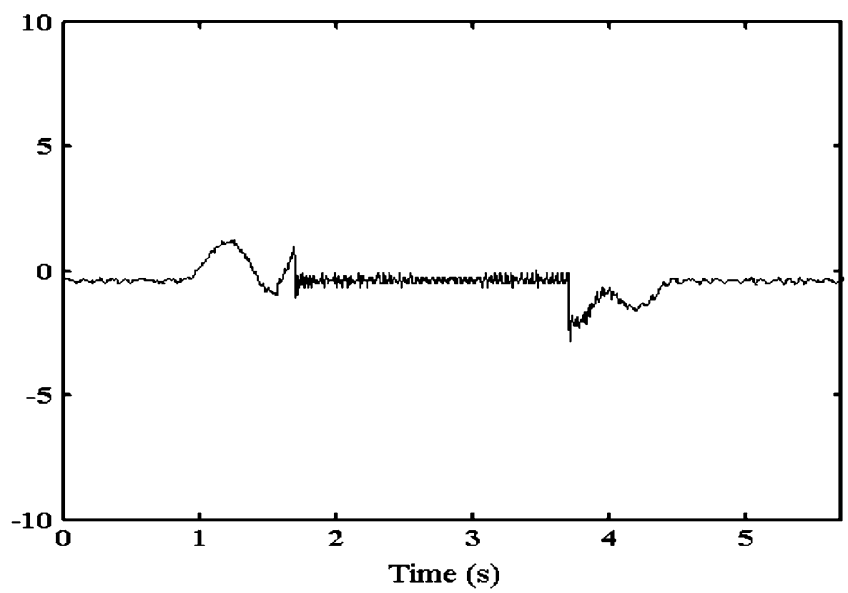

(e)

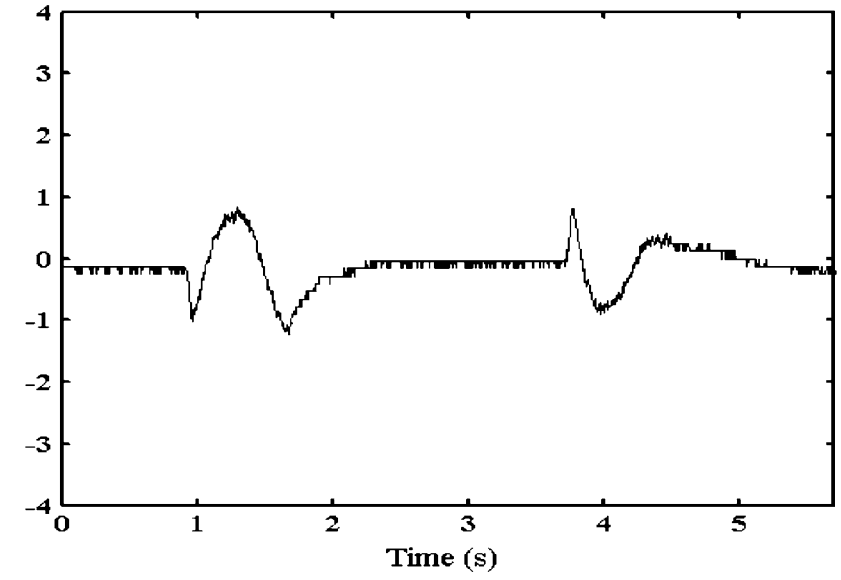

(b)

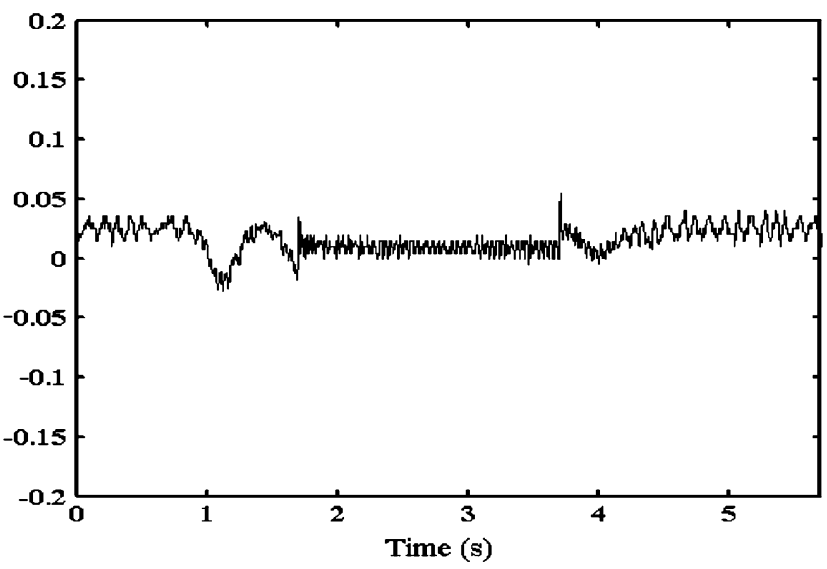

(d)

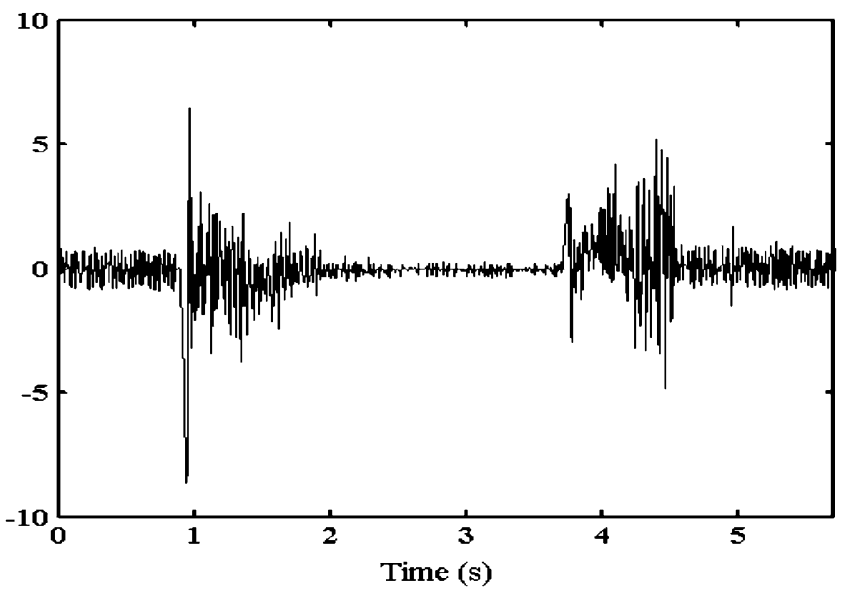

(f)

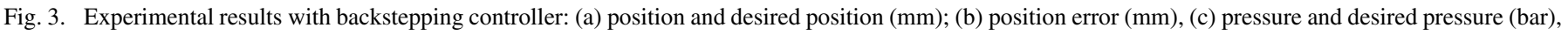
(d) pressure error (bar), (e) control input $u_{P}(\mathrm{~V})$, and (f) control input $u_{N}(\mathrm{~V})$.

through the signal conditioning unit before being read by the 16-bit analog/digital converter. Two pressure sensors are used, their precision is equal to $700 \mathrm{~Pa}(0.1 \%$ of the extended measurement) and their combined nonlinearity and hysteresis is equal to $\pm 0.1 \%$ of the extended measurement. The cylinder velocity is determined by analog differentiation and low-pass filtering of the output of the position given by an analog potentiometer (its precision and repeatability is equal to $10 \mu \mathrm{m}$ and its linearity is $0.05 \%$ of the extended measurement). The acceleration information is obtained by numerically differentiating the velocity.

The gains $c_{1}=120, c_{2}=40, c_{3}=20$, and $c_{4}=200$ have been tuned in order to minimize the position tracking error in presence of model uncertainties. These values ensure good static and dynamic performance. Some experiment results are provided here to demonstrate the effectiveness of the backstepping controller. 


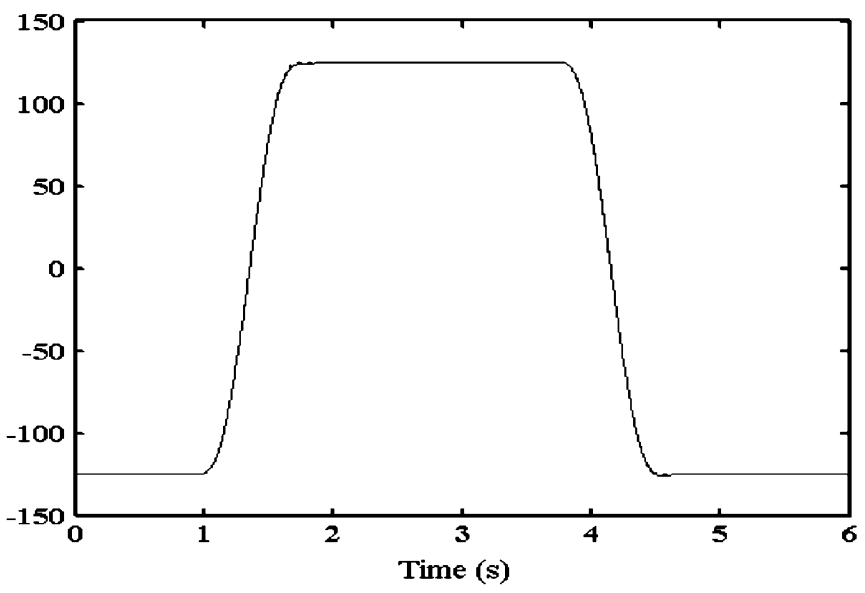

(a)

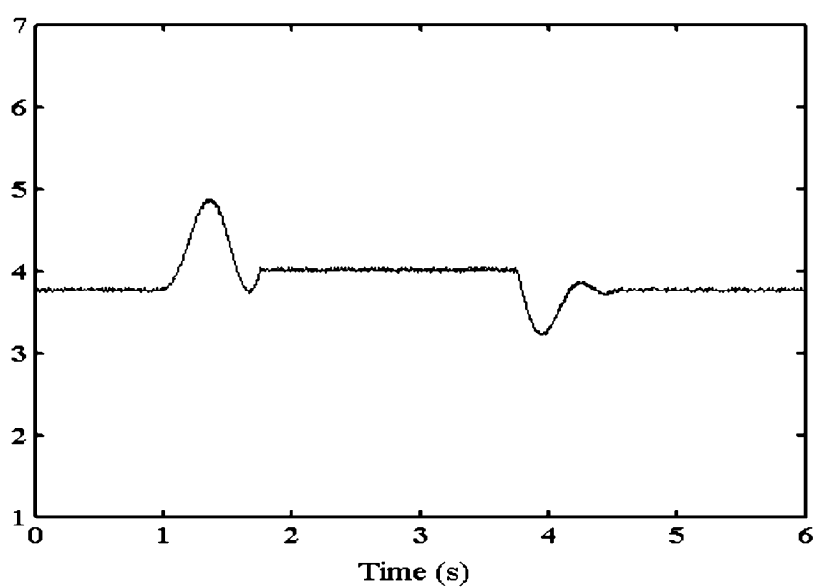

(c)

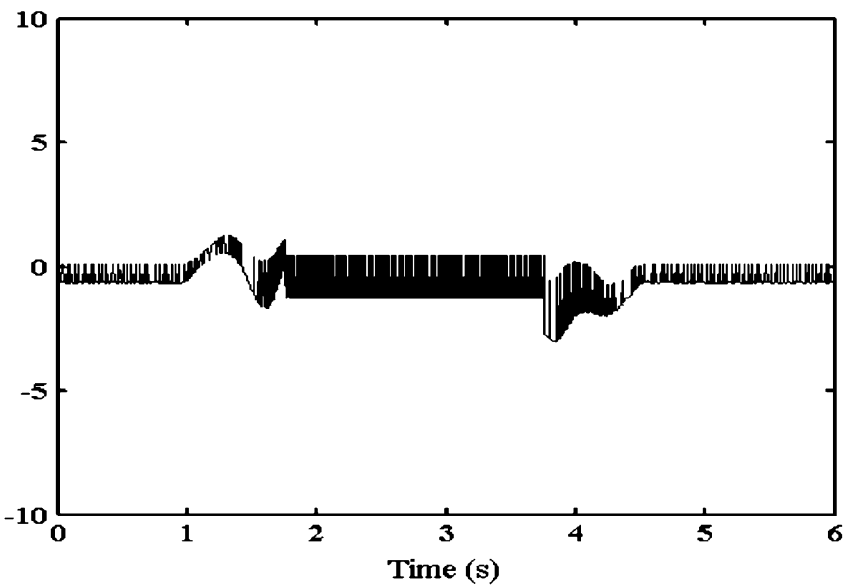

(e)

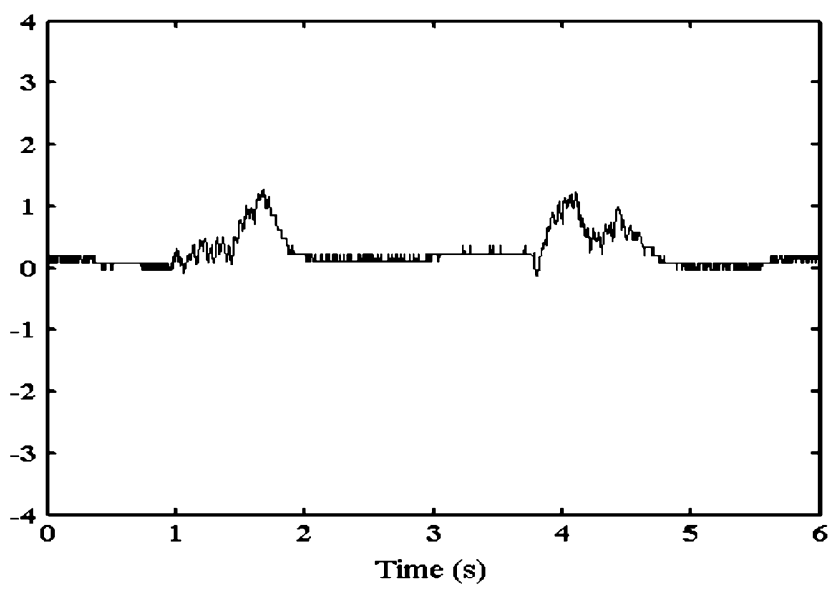

(b)

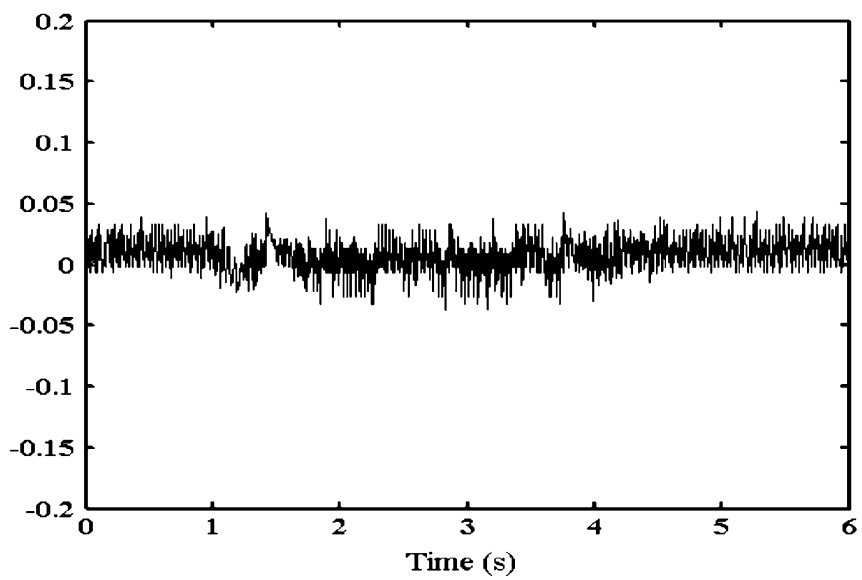

(d)

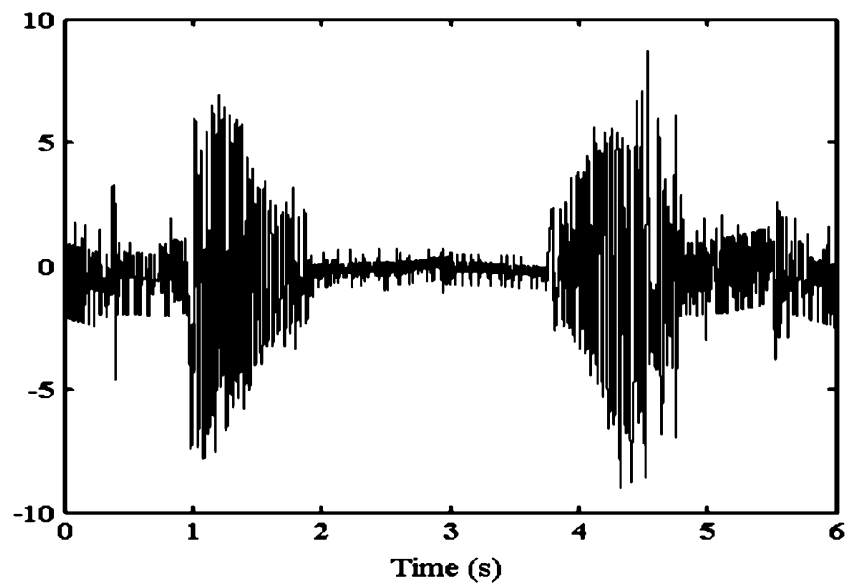

(f)

Fig. 4. Experimental results with sliding mode controller: (a) position and desired position (mm), (b) position error (mm), (c) pressure and desired pressure (bar), (d) pressure error (bar), (e) control input $u_{P}(\mathrm{~V})$, and (f) control input $u_{N}(\mathrm{~V})$

Fig. 3 shows the position, the desired position, the position error, the pressure in chambers $P$, the desired pressure in chamber $P$, the pressure error, and the two control inputs $u_{P}$ and $u_{N}$.

From the experimental results, perfect tracking responses are obtained for the position and pressure in chamber $P$ due to the robust control characteristics of the backstepping controller. The position tracking error is less than $1.5 \mathrm{~mm}$, which is better than a classical nonlinear control law [10]. (The control law in [10] has been implemented on the same experimental setup, in the same conditions. In this case, the maximum position error is about $5.54 \mathrm{~mm}$.) The pressure tracking error is no more than 54 mbar.

Fig. 3(f) displays the control input $u_{N}$. The noise is due to the acceleration signal obtained by differentiating the velocity numerically. Future work will focus on the exact robust differ- 
entiation via sliding mode technique [25]. Fig. 3(e) shows the control input $u_{P}$. The signal is smooth (the computation of $u_{p}$ does not need the acceleration signal).

The sliding mode controller is applied to control the electropneumatic system for comparison. The experimental conditions are the same as previous. The objective consists of tracking the desired position and pressure with high accuracy in spite of model uncertainties. For the position control $k_{1}=120$ and for the pressure control $k_{2}=4 \times 10^{5}$, the gains have been tuned in order to minimize the position and pressure tracking errors.

The responses of the position of the piston, the pressure in chamber $p$ and the two control laws $u_{P}$ and $u_{N}$, are shown in Fig. 4.14tcst05-smaoui

The robust control characteristics of the sliding mode controller can be observed. The maximum position tracking error is about $1.27 \mathrm{~mm}$. This error equals about $0.51 \%$ of the total displacement magnitude. In steady state, the average position error is about $100 \mu \mathrm{m}$. The pressure tracking error is very low: its maximum value is about 43 mbar.

Therefore, this control law seems more efficient than feedback linearization [2]. However, the chattering phenomena in the control laws [see Fig. 4(e) and (f)] are undesirable and seem considerably to decrease the lifetime of some components. So, from this point of view, backstepping controllers seem more useful than sliding mode controllers.

\section{CONCLUSION}

This paper has successfully demonstrated the application of a MIMO backstepping controller and a MIMO sliding mode controller to control the position and the pressure (in one chamber) of an electropneumatic system. First, the mathematical model of the electropneumatic system was introduced. Then, the theoretical bases of the controllers were described in detail. Then, experiments were carried out to test the effectiveness of the proposed controllers.

Satisfactory control performance has been obtained by both the backstepping and sliding-mode controllers. The chattering phenomenon does not exist in the backstepping controller. So, the backstepping controller is more suitable to control an electropneumatic system. Future work will focus on higher order sliding modes. In fact, as is indicated in [26], higher order sliding modes preserve or generalize the main properties of standard sliding mode and also remove the chattering effect.

\section{REFERENCES}

[1] K. A. Edge, "The control of fluid power systems responding to the challenge," J. Syst. Contr. Eng., vol. 211, no. 12, pp. 91-110, Mar. 1997.

[2] X. Brun, S. Sesmat, D. Thomasset, and S. Scavarda, "A comparative study between two control laws of an electropneumatic actuator," in Proc. Euro. Contr. Conf., 1999, [CD ROM], ref. F1000-5.

[3] T. Kimura, S. Hara, T. Fujita, and T. Kagawa, "Feedback linearization for pneumatic actuator systems with static fiction," Contr. Eng. Practice, vol. 5, no. 100, pp. 1385-1394, Oct. 1997.

[4] M. Parnichkun and C. Ngaecharoenkul, "Kinematics control of a pneumatic system by hybrid fuzzy PID," Mechatronics, vol. 11, no. 8, pp. 1001-1023, Dec. 2001.
[5] B. Li, Z. Li, and Y. Xu, "Study on adaptive control for a pneumatic position servo system," Adv. Modeling Anal., vol. 49, no. 2, pp. 21-28, Mar. 1997.

[6] F.-J. Lin, R.-F. Fung, and R.-J. Wai, "Comparison of sliding-mode and fuzzy neural network control for motor-toggle servomechanism," IEEE/ASME Trans. Mechatronics, vol. 3, no. 4, pp. 302-318, Dec. 1998.

[7] M. Zribi, H. Sira-Ramirez, and A. Ngai, "Static and dynamic sliding mode control schemes for a permanent magnet stepper motor," in International Journal of Control. New York: Taylor \& Francis, 2001, pp. 103-117.

[8] M. Mattei, "Robust regulation of the air distribution into an arc heater," J. Process Contr., vol. 11, no. 3, pp. 285-297, Jun. 2001.

[9] X. Brun, D. Thomasset, and S. Scavarda, "Hybrid control for switching between position and force tracking," in Proc. 4th Int. Symp. Fluid Power Transmission Contr., 2003, pp. 44-49.

[10] X. Brun, D. Thomasset, and E. Bideaux, "Influence of the process design on the control strategy: Application in electropneumatic field," Contr. Eng. Practice, vol. 10, no. 7, pp. 727-735, Jul. 2002.

[11] J. L. Shearer, "Study of pneumatic processes in the continuous control of motion with compressed air," Trans. Amer. Soc. Mech. Eng., vol. 78, pt. I, II, pp. 233-249, Feb. 1956.

[12] K. Araki, "Effects of valve configuration on a pneumatic servo," in Proc. Int. Fluid Power Symp., 1981, pp. 271-290.

[13] E. Richard and S. Scavarda, "Comparison between linear and nonlinear control of an electropneumatic servodrive," J. Dyn. Syst. Measurement Contr., vol. 118, no. 2, pp. 245-252, Jun. 1981.

[14] S. Sesmat and S. Scavarda, "Static characteristics of a three way servovalve," in Proc. 12th Conf. Fluid Power Technol., 1996, pp. 643-652.

[15] M. Belgharbi, D. Thomasset, S. Scavarda, and S. Sesmat, "Analytical model of the flow stage of a pneumatic servodistributor for simulation and nonlinear control," in Proc. 6th Scandinavian Int. Conf. Fluid Power, 1999, pp. 847-860.

[16] S. S. Ge, C. C. Hang, and T. Zhang, "Adaptive neural network control of nonlinear systems by state and output feedback," IEEE Trans. Syst., Man, Cybern. B. Cybern., vol. 29, no. 6, pp. 818-828, Dec. 1999.

[17] — , "Nonlinear adaptive control using neural networks and its application to CSTR systems," J. Process Contr., vol. 9, no. 4, pp. 313-323, Aug. 1999

[18] M. Fliess, J. Levine, P. Martin, and P. Rouchon, "Flatness and defect of non-linear systems: Introductory, theory and applications," Int. J. Contr., vol. 61, no. 6, pp. 1327-1361, Jun. 1995.

[19] M. Krstić, I. Kanellakopoulos, and P. Kokotović, Nonlinear and Adaptive Control Design. New York: Wiley, 1995, p. 563.

[20] A. Alleyne and R. Liu, "Systematic control of a class of nonlinear systems with application to electrohydraulic cylinder pressure control," IEEE Trans. Contr. Syst. Technol., vol. 8, no. 4, pp. 623-634, Jul. 2000.

[21] H. Khalil, Nonlinear Systems, 3rd ed. Englewood Cliffs, NJ: Prentice-Hall, 2001, p. 750.

[22] J. J. E. Slotine and W. Li, Applied Nonlinear Control. Englewood Cliffs, NJ: Prentice-Hall, 1991, p. 461.

[23] V. I. Utkin, "Variable structure systems with sliding modes," IEEE Trans. Autom. Contr., vol. 26, no. 2, pp. 212-222, Apr. 1977.

[24] M. Bouri and D. Thomasset, "Sliding control of an electropneumatic actuator using an integral switching surface," IEEE Trans. Contr. Syst. Technol., vol. 9, no. 2, pp. 368-375, Mar. 2001.

[25] A. Levant, "Robust exact differentiation via sliding mode technique," Automatica, vol. 34, no. 3, pp. 379-384, Mar. 1998.

[26] A. Levant, "Universal single-input-single-output (SISO) sliding-mode controllers with finite-time convergence," IEEE Trans. Autom. Contr., vol. 46, no. 9, pp. 1447-1451, Sep. 2001.

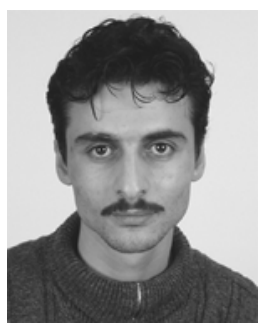

Mohamed Smaoui was born in Sfax, Tunisia, in 1976. He received the electrical engineering degree from the National Engineering School of Sfax, Sfax, Tunisia, in 2000, and the M.Sc. and D.Sc. degrees in automation from the Institut National des Sciences Appliquiées de Lyon (INSA), Lyon, France, 2001 and 2004, respectively.

He has been an Associate Professor at the Department of Mechanical Engineering at INSA, since 2005. His research interests include advanced control of mechanical systems. 


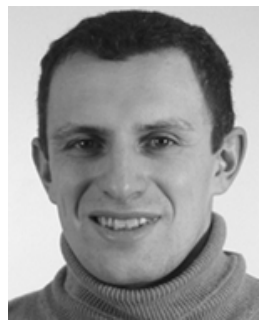

Xavier Brun was born in Roanne, France, in 1973. $\mathrm{He}$ received the $\mathrm{Ph} . \mathrm{D}$. degree from the Institut National des Sciences Appliquiées de Lyon (INSA), Lyon Scientific and Technical University, Lyon, France, in 1999.

He has been an Associate Professor at the Laboratoire d'Automatique Industrielle (LAI), INSA, since 2001. His current interests include the implementation and comparison of controls laws for fluid power actuators.

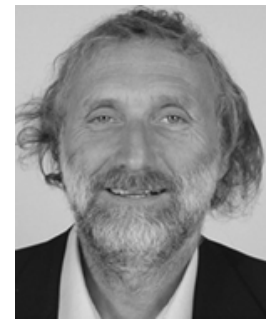

Daniel Thomasset is currently a Professor at the Laboratoire d'Automatique Industrielle (LAI), Lyon, France, where he is the Head of the Fluid Power, Transport and Robotic Team. His research interests include control and sizing of fluid power system for transport application. 